\title{
Therapeutic efficacy of platelet-rich plasma injection compared to corticosteroid injection in plantar fasciitis: A systematic review and meta- analysis
}

\author{
Wafi Mohammed ${ }^{\mathrm{a}}$, Salma Farah ${ }^{\mathrm{b}}$, Mujtaba Nassiri ${ }^{\mathrm{a}, *}$, Johnny McKenna ${ }^{\mathrm{a}}$ \\ ${ }^{a}$ Tallaght University Hospital, Tallaght, Dublin 24, Ireland \\ ${ }^{\mathrm{b}}$ Faculty of Medicine, University of Khartoum, Khartoum, Sudan
}

A R T I C L E I N F O

\section{Keywords:}

Platelet-rich plasma

Plantar fasciitis

Corticosteroids

Injections

Foot

\begin{abstract}
A B S T R A C T
Background: This study summarizes all literature assessing the long term effects of platelet-rich plasma (PRP) injection compared to corticosteroid injection to relieve pain and improve function in Plantar Fasciitis patients. Materials and methods: This is a PRISMA compliant systematic review of 5 databases and include a meta-analysis of Randomized Controlled Trial data comparing the two injections.

Results: Ten prospective trials were included with total number of 543 participants. The PRP group had significantly better pain scores at 3 months and 6 months follow-up.

Conclusion: PRP injections provide better pain relief, compared to corticosteroids, in patients with plantar fasciitis.
\end{abstract}

\section{Introduction}

\subsection{Background}

Plantar fasciitis is considered the commonest cause of heel pain contributing to an estimate of one million patient visits per year to office based physician or outpatient department between 1995 and 2000 in the US, and account for $1 \%$ of visits to orthopaedic surgeon. ${ }^{1}$ Economic evaluation study carried out by Tong K. $\mathrm{B}^{2}$ and his colleagues found that the annual costs estimate of plantar fasciitis treatment is around \$284 million in the United States, but additional costs from lost work and wages, social burden, and psychologic burden, was not included in this study.

\subsection{Anatomy and histological structure}

Plantar fascia is a thick, sheet-like connective tissue, located in the under surface of the foot originating from the medial calcaneal tubercle and stretch forward to the head of metatarsophalangeal joints capsule. Histologically, It is composed of superimposed collagen fibres, with intermingled elastin fibres. ${ }^{3}$ The plantar fascia's main function include the maintenance of medial arch foot, in addition, to contribution to reformation of the foot facilitating occurrence of toe off phase,via windlass mechanism, during gait cycle. ${ }^{4}$

\subsection{Pathophysiology}

In the past, plantar fasciitis was presumed to be an inflammatory condition affecting plantar fascia and the name indicated that, as the suffix "-itis", inherently implies an inflammatory disease.

But the exact underlying aetiology of plantar fasciitis was not well known, therefor this term was frequently used interchangeably with "heel spur syndrome" ${ }^{5}$ and "painful heel syndrome". ${ }^{6}$

Later basic science studies found that inflammation is not always present and therefore the term "plantar fasciitis" was considered to be a misnomer. ${ }^{7}$ Further studies deduced that the underlying pathology in plantar fasciitis is of degenerative nature, which was supported by both imaging and histopathological studies. Grasel et al. studied series of MRI images of patients diagnosed clinically with plantar fasciitis, features of fascial micro tears resulting in peri-fascial oedema was found with no substantial evidence to support inflammation as the underlying cause, supported by linearity and low prevalence of high MRI signal intensity within the plantar fascia. ${ }^{8,9}$

Histopathological studies assessing plantar fascia specimens obtained from patients who underwent fasciotomy to treat intractable plantar fasciitis was performed by lemont et al. ${ }^{7}$ The findings include myxoid degeneration with fragmentation and degeneration of the plantar fascia and bone marrow vascular ectasia, which is suggestive of a degenerative process and the term fasciosis without inflammation was

\footnotetext{
* Corresponding author. Department of Trauma \& Orthopaedics, Tallaght University Hospital, Belgard Square North, Tallaght, Dublin 24, D24NR0A, Ireland.

E-mail address: Nassiri2000@yahoo.co.uk (M. Nassiri).
} 
coined by the author. ${ }^{7}$

The exact mechanism resulting in plantar fascia to undergo this degenerative process is not fully understood, however, repetitive trauma resulting in micro tears was implicated as the underlying cause. Several risk factors have been associated with development of plantar fasciitis.

Well known independent risk factors, which showed strong positive correlation with development of plantar fasciitis, include obesity, prolonged work related weight bearing and reduced ankle dorsiflexion. ${ }^{10}$ Plantar fasciitis has also been associated with, old age, and biomechanical abnormalities in the foot, such as tight Achilles tendon, pes cavus, and pes planus. ${ }^{11}$

Plantar fasciopathy is a self-limiting condition, however, the impact, of pain associated with plantar fasciitis, on health related quality of life is profound leading frustrated patients to seek treatment without accepting the self-limited nature of the condition which can extend for up to 1 year. ${ }^{12,13}$ Factors associated with increased risk of prolonged symptoms include: overweight ${ }^{10}$, bilateral involvement, and when there is a long delay before seeking medical attention. ${ }^{14,15}$

\subsection{Diagnosis}

\subsubsection{History and clinical examination}

Diagnosis of plantar fasciitis is based on history and clinical examination with little contribution attained by further imaging modalities like MR images and Ultrasonography (US), except in recalcitrant cases. ${ }^{16}$ Patients with Plantar fasciitis report gradual onset of plantar heel pain, which is especially worse with the first steps in the morning and after prolonged rest. ${ }^{17}$ Pain has been found to progressively decrease with activity but worsens towards the end of the day. ${ }^{18}$ Most cases of plantar fasciitis present unilaterally, However, Bilateral presentation has been found to affect up to $30 \%$ of cases. ${ }^{19}$

Tenderness to palpation of the medial calcaneal tuberosity is a hallmark of plantar fasciopathy, but tenderness of the whole plantar fascia may also be seen. ${ }^{17}$ Further clinical examination of possible risk factors for plantar fasciitis can be appreciated during assessment, including: reduced ankle joint dorsiflexion, tightness of hamstring muscles, excessive foot protonation, rear-foot eversion, and pes planus or cavus foot deformities. ${ }^{20}$ Moreover, Provocation of pain can be elicited clinically when patient stands on their toes or with passive dorsiflexion of Metatarsophalangeal joints due to the windlass mechanism. ${ }^{21}$

During the course of patient assessment, it is imperative to rule out other causes of plantar heel pain which can be appreciated during history taking and clinical examination in the majority of cases However, further diagnostic studies might be required to rule out other conditions, such as plantar fascia tears, entrapment of the first branch of the lateral plantar (Baxter's) nerve, heel pad atrophy, plantar fibromatosis, tarsal tunnel syndrome, calcaneal stress fractures, and plantar vein thrombosis. ${ }^{17}$

\subsubsection{Diagnostic imaging studies}

Although plantar fasciitis is primarily a clinical diagnosis, imaging modalities can be utilized to confirm diagnosis and to rule out other possible causes of heel pain.

Lateral non-weight bearing plain radiograph is relatively inexpensive with low radiation exposure. The principal finding is plantar fascia thickness and fat pad abnormalities. ${ }^{22}$ Moreover, other causes of heel pain can be detected readily using plain film radiograph like calcaneal stress fractures or bony erosions of the plantar fascial attachment and Achilles tendon insertion, which would suggest enthesopathy of these structures, leading to inclusion of seronegative spondyloarthropathy as an important differential diagnosis. ${ }^{23}$ It is important to note that the presence of calcaneal spur is very nonspecific and is not always associated with plantar fasciitis. Key feature on MR imaging in plantar fasciopathy are a diffuse thickening of the fascia associated with areas of low signal intensity replacement and other areas of intermediate signal intensity or linear band or lobules of high signal intensity. In the later stages of the disease, fluid sensitive sequences will exhibit high signal changes in the surrounding soft tissues. ${ }^{24}$

Ultrasound images reflect the abnormalities detected by MR images. The thickness of the plantar fascia is increased with a superior to inferior dimension $>4.5 \mathrm{~mm}$. Additionally, disorganization of the normal reflective structure alongside loss of the normal ligament architecture is considered to be an important feature highly suggestive of plantar fasciitis. Bony involvement, however, is not readily appreciated in US, compared to MRI, although interruption of the bony cortex is detectable in more advanced stages of the disease. ${ }^{23}$

\subsection{Treatment}

\subsubsection{Conservative treatment}

Stretching protocols of the plantar fascia and Achilles tendon were proven to be effective in relieving pain among patients diagnosed with plantar fasciitis. Despite the uncertainty of benefit from combined stretching of both plantar fascia and Achilles tendon compared to isolated stretching of one structure only, stretching of both seems to be beneficious and usually considered. ${ }^{25}$

Taping is an additional modality that is used in conjunction with stretching exercises. Several modalities described, with most commonly used varieties are:

a) Low-dye taping: the most commonly used technique; the main aim is to reduce medial heel pressure by lifting the navicular bone. ${ }^{26}$

b) Calcaneal taping: The second most common taping technique, the main aim is to reposition the calcaneus to neutral alignment which is, theoretically suggested, to improve biomechanical position of the foot. $^{26}$

Previous studies showed a short-term improvement of symptoms with both taping techniques, and use of either taping technique in conjunction with other conservative treatment options is recommended. ${ }^{27}$

Foot orthoses, both custom and prefabricated, were proved to improve pain from plantar fasciitis when used in conjunction with stretching exercises. ${ }^{28}$

Night splints are used in the treatment of plantar fasciopathy by placing the ankle joint in neutral position which lead to advantageous biomechanical position, correcting the abnormal protonation implicated as predisposing factor for development of plantar fasciitis and reduce the nocturnal contracture of gastrocnemius-soleus complex which eventually lead to increased range of movement of the ankle joint. ${ }^{29}$ The orthosis are available as prefabricated or custom made construct with no difference in outcome demonstrated between the different forms ${ }^{29,30, .31}$

\subsubsection{Extracorporeal shock wave lithotripsy (ESWL)}

ESWL has been used in treatment of plantar fasciitis where no improvement was achieved following conservative management. ESWL is believed to stimulate soft tissue healing process but the exact mechanism is not fully understood.

A Systematic review carried out by Speed et al. noted that, pulsed radial ultrasound waves and focused US waves of high intensity are effective for plantar fasciitis compared to low intensity US waves. ${ }^{32}$

\subsubsection{Corticosteroid injection (CS)}

CS injection has been a longstanding acceptable modality of treatment in cases of plantar fasciitis with proven effectiveness, ${ }^{33}$ as it acts as an anti-inflammatory addressing the inflammatory component of the condition, however, the duration of beneficial effect is still controversial ranging from 4 weeks up to 2 years. ${ }^{34,35}$ The main concerns associated with CS injections are the risk of plantar fascia rupture ${ }^{36}$ and a suggested theoretical risk of heel pad atrophy which has not been 
proven in previous studies. ${ }^{37}$

Despite the undisputed effectiveness of CS injection in PF, there is controversy about the long term effect which is not achievable without addressing the underlying degenerative process. Lemont et al. suggested that the use of steroid in plantar fasciitis should be questioned in cases with absent evidence of inflammation due to the proven degenerative process implicated as the underlying pathology for the condition. ${ }^{6}$

Traditionally, plantar fascia injection was done using the landmark technique but more recently US guided injection has been more popular with different techniques described. ${ }^{38}$

\subsubsection{Platelet-rich plasma injection}

Platelets are small discoid blood cells derived from megakaryocytes in bone marrow with a lifespan of 7-10 days. Platelets lack nucleui but contain two types of granules, dens and alpha granules. Clotting and growth factors are contained in the alpha granules and released upon platelets activation, by thrombin, promoting eventually the healing process by stimulating the inflammatory cascade. ${ }^{39}$

Platelet-rich plasma (PRP) is an autologous concentrate of human platelets prepared by centrifuging the whole blood resulting in a small amount of plasma with high concentration of platelets. Normal platelet concentration in the blood is 200,000 platelets/ $\mu 1$. A minimum increase by 4 times of the baseline is needed in order to achieve clinical efficacy (1million platelets $/ \mu \mathrm{l}$ ) as proven by different studies. Different systems are used to prepare PRP with slight variability in their ability to concentrate platelets depending on the manufacturer's system used. ${ }^{40}$ The concentrates contain several growth factors and bioactive proteins released by platelets which attract macrophages, mesenchymal stem cells, and osteoblasts which induce several processes that collectively lead to removal of necrotic tissue, and to promote the healing process such as cellular proliferation, matrix formation, osteoid production, and collagen synthesis ${ }^{40(41)}$. The main growth factors contained in these granules are transforming growth factor beta (TGF $\beta$ ), vascular endothelial growth factor (VEGF) platelet-derived growth factor (PDGF), and epithelial growth factor (EGF). ${ }^{40}$ A summary of growth factors action is given in (Table 1).

Concerns about immunogenic reaction or infection transfer are abolished due to the autologous nature of PRP. Moreover, no previous studies demonstrate carcinogenesis or tumour growth potential. Theoretically growth factors acts on cell membrane receptor rather than the cell nucleus resulting in normal gene expression. ${ }^{41}$ Many studies reported beneficial long term effect of PRP injection in many soft tissue conditions including plantar fasciitis. ${ }^{44}$

\subsection{Aim of systematic review \& meta-analysis and rationale}

The aim of this study was to assess the long term efficacy of PRP injection compared to corticosteroid injection in relieving pain and

Table 1

Summary of the actions of growth factors released by platelets.

\begin{tabular}{|c|c|}
\hline Growth factor & Action \\
\hline $\begin{array}{l}\text { Platelet-derived growth factor } \\
\qquad(\text { PDGF })^{39}\end{array}$ & $\begin{array}{l}\text { Stimulates cell replication } \\
\text { Promotes angiogenesis } \\
\text { Promotes epithelialisation } \\
\text { Promotes granulation tissue formation }\end{array}$ \\
\hline $\begin{array}{l}\text { Transforming growth factor } \\
\qquad(\text { TGF } \beta)^{42}\end{array}$ & $\begin{array}{l}\text { Promotes formation of extracellular matrix } \\
\text { Regulates bone cell metabolism }\end{array}$ \\
\hline $\begin{array}{l}\text { Vascular endothelial growth } \\
\text { factor (VEGF) }\end{array}$ & Promotes angiogenesis \\
\hline $\begin{array}{l}\text { Epithelial growth factor } \\
\qquad(\mathrm{EGF})^{41}\end{array}$ & $\begin{array}{l}\text { Promotes cell differentiation stimulates re- } \\
\text { epithelialisation, angiogenesis and collagenase } \\
\text { activities }\end{array}$ \\
\hline $\begin{array}{l}\text { Fibroblast growth factor } \\
\qquad(\mathrm{FGF})^{41}\end{array}$ & $\begin{array}{l}\text { Promotes proliferation of endothelial cells and } \\
\text { fibroblasts Stimulates angiogenesis }\end{array}$ \\
\hline
\end{tabular}

consequently improving function among patients with plantar fasciitis. The continuous generation of prospective trials studying the effect of PRP injection in plantar fasciitis compared to the current, most commonly used treatment (CS injection), promoted the pursue of systematic and statistical analysis of current evidence available in order to reach a conclusion of the outcome expected from PRP injection.

Primary objective: Do patients with plantar fasciitis treated with PRP injection have better long term pain relief compared to patients treated with steroid injections.

\section{Materials and methods}

\subsection{Reporting method}

The Preferred Reporting Items for Systematic Reviews and Metaanalyses (PRISMA) guidelines were followed (Table 2). The systemic review protocol was registered in the International Prospective Register of Systematic Reviews (PROSPERO) (Registration number: CRD42019147733). The protocol is available in the appendix.

\subsection{Data sources}

Systematic literature searches were performed of all published articles up to August 2019 utelizing: MEDLINE (via PubMed), ExcerptaMedica (EMBASE), clinicaltrials.gov, The Cochrane Library and conference proceeding via the web of Science core collection database.

Databases were searched from their establishment to 1st of August 2019, for randomized controlled trials (RCTs) and prospective comparative studies comparing PRP with steroid injections as treatments for Plantar fasciitis.

No language restriction was applied. Manual search of the reference lists of included studies and relevant reviews was done to identify and include eligible studies as applicable.

\subsection{Search strategy}

Keywords identified from relevant previously published studies were used, including: Plantar Fasciitis, Heel Spur Syndrome, Chronic Plantar Fasciitis, Fasciitis, plantar fasciosis, plantar fasciopathy, Platelet-Rich Plasma OR Platelet-Rich fibrin, autologous blood product, autologous conditioned plasma, Steroids, Triamcinolone, Methylprednisolone, Corticosteroid.

The search strategy was designed and altered as necessary and appropriate to the different databases.

\subsection{Outcome of interest}

Mean Visual analogue score of PRP injection group at 4 weeks, 3 months, and 6 months.

Mean of visual analogue score of CS injection group at 4 weeks, 3 months, and 6 months.

\subsection{Eligibility criteria}

Eligible studies was decided based on the following criteria:

\author{
2.5.1. Inclusion criteria \\ trial). \\ Prospective randomised trial (RCT, open-label and Quasi controlled
}

1) Adult patients diagnosed with plantar fasciitis

2) Failure of conservative management in form of stretching exercises, non-steroidal anti-inflammatory medications and heel pads for at least 3 months

3) Ethical approval and consents obtained from patients participated in 


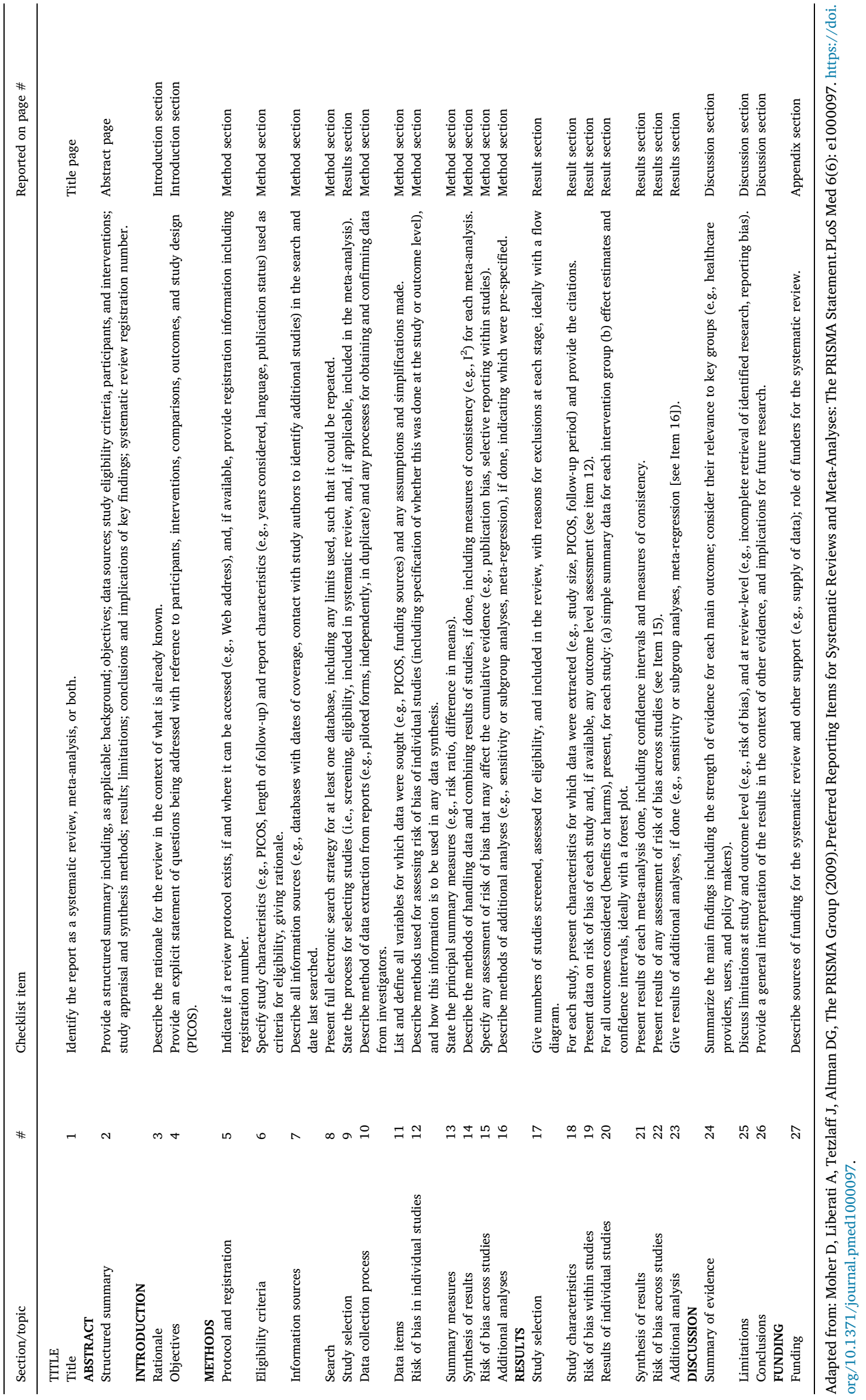




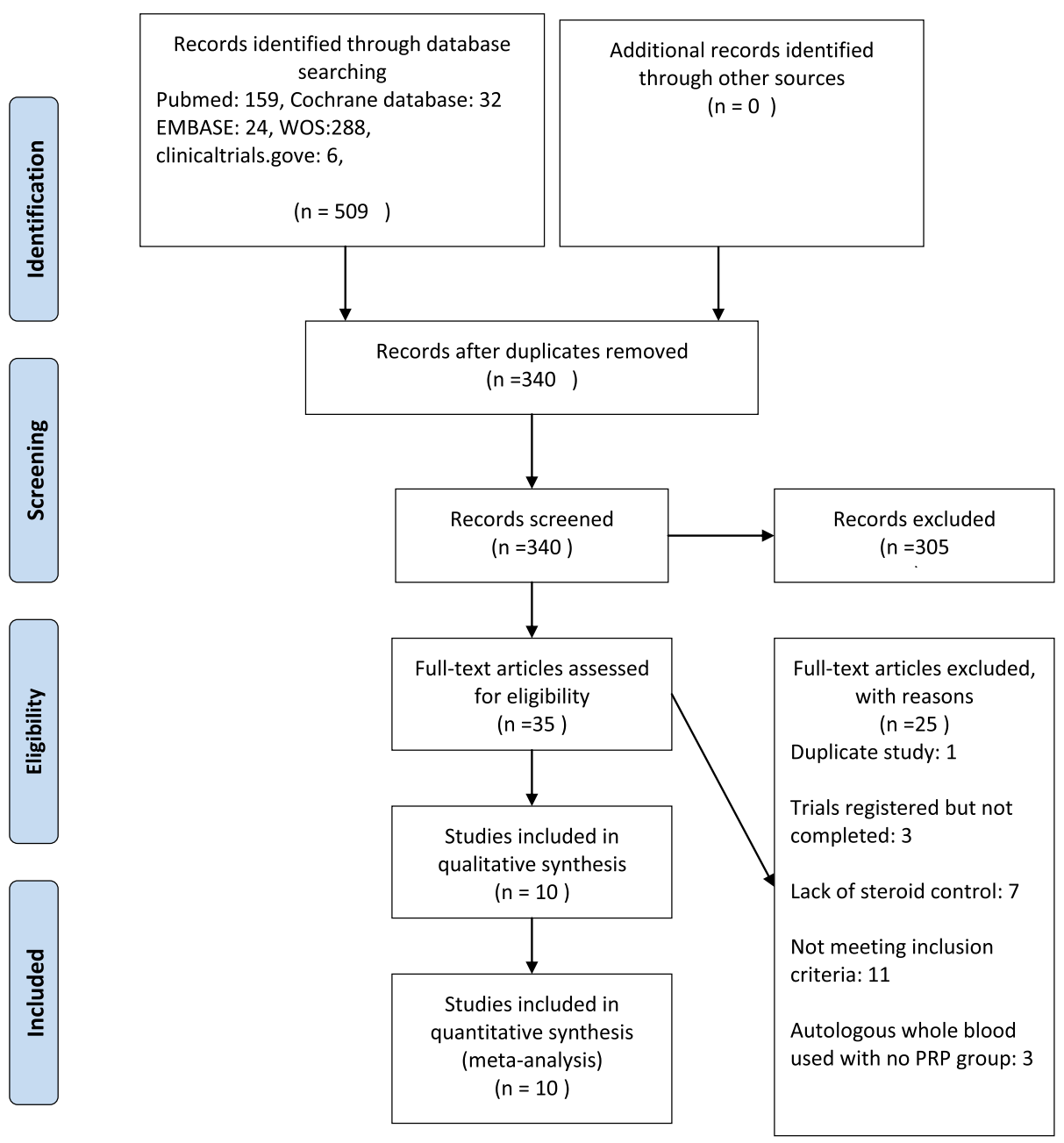

Fig. 1. Flow diagram of study selection process.

included studies.

4) Visual analogue score used for baseline and outcome measurement.

5) Post injection stretching of the Achilles tendon and plantar fascia were educated to all patients.

\subsubsection{Exclusion criteria}

1) History of surgical intervention for heel pain.

2) History of systemic disorder like: Diabetes Mellitus, gout or Rheumatoid arthritis, Haematological disease.

3) Pregnancy.

4) Patients receiving NSAID medication within one week of the injection.

\subsection{Data extraction}

Articles meeting the eligibility criteria were retrieved and full text review was performed by two independent reviewers. Data extraction from eligible studies was executed using standardized templates by one reviewer and verified by the second reviewer with any disparity in opinion resolved by discussion. Variables included in the abstraction forms were: Aim of study, Study design, number of participants in each arm, Informed consent obtained?, Ethical approval, geographical location, Mean VAS at 4 weeks, 3 months and 6 months after intervention in each arm with standard deviation if available.

\subsection{Risk of bias assessment}

Risk of bias for individual studies were carried out using the Cochrane Collaboration tool for assessment (Higgins and Green 2011) by two reviewers independently. Studies were assessed using 7 domains: Sequence generation, Allocation concealment, blinding of participants and personnel, blinding of outcome assessment, selective outcome reporting, incomplete outcome data, other source of bias. Any disagreement between the reviewers was resolved by discussion and consultation with the third reviewer if needed.

\subsection{Statistical analysis}

The pooled results were presented as mean differences (MD) with their corresponding 95\% confidence intervals (CIs). Pooled estimates of mean differences of VAS between the intervention groups were calculated using a random effects model (inverse variance method) to account for the variability due to clinical heterogeneity.

Heterogeneity was judged using the $\mathrm{tau}^{2}$ and $\mathrm{chi}^{2}$ test, $\mathrm{P}$ value $<0.050$ was considered to be significant. The degree of heterogeneity was assessed using $\mathrm{I}^{2}$ test. Interpretation of $\mathrm{I}^{2}$ index was stratified as follow:

- 0\%-40\%: heterogeneity might not be important;

- 30\%-60\%: may represent moderate heterogeneity;

- 50\%-90\%: may represent substantial heterogeneity;

- 75\%-100\%: considerable heterogeneity. 
Table 3

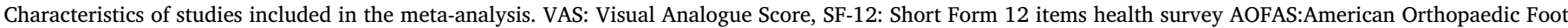

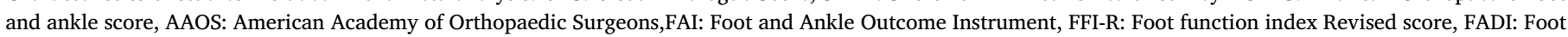
and Ankle Disability Index, FSHQ: Foot health status questionnaire.

\begin{tabular}{|c|c|c|c|c|c|c|c|c|}
\hline \multirow[t]{2}{*}{ Reference } & \multirow[t]{2}{*}{ Design } & \multirow{2}{*}{$\begin{array}{l}\text { Geographical } \\
\text { location }\end{array}$} & \multirow{2}{*}{$\begin{array}{l}\text { Consent obtained } \\
\text { from participants }\end{array}$} & \multirow{2}{*}{$\begin{array}{l}\text { Ethical } \\
\text { approval }\end{array}$} & \multicolumn{2}{|l|}{ Participants } & \multirow[t]{2}{*}{ Outcome measured } & \multirow{2}{*}{$\begin{array}{l}\text { Duration of follow } \\
\text { up }\end{array}$} \\
\hline & & & & & PRP injection & CS injection & & \\
\hline $\begin{array}{l}\text { Shetty S.H et al } \\
\quad 2019^{45}\end{array}$ & $\begin{array}{l}\text { Randomised, double } \\
\text { blinded, three arms, } \\
\text { parallel }\end{array}$ & $\begin{array}{l}\text { India. } \\
\text { Hospital based }\end{array}$ & Yes & Yes & 30 & 30 & $\begin{array}{l}\text { VAS } \\
\text { Roles and Maudsley } \\
\text { SF-12 form }\end{array}$ & $\begin{array}{l}1 \text { and } 3 \text { weeks } \\
3,6,12 \text {, and } 18 \\
\text { months }\end{array}$ \\
\hline $\begin{array}{c}\text { Jain S. K. et al } \\
2018^{46}\end{array}$ & $\begin{array}{l}\text { Randomised, open label, } \\
\text { two arms, parallel }\end{array}$ & $\begin{array}{l}\text { India. } \\
\text { Hospital based }\end{array}$ & Not specified & Yes & 40 & 40 & $\begin{array}{l}\text { VAS } \\
\text { Roles \&Maudsley } \\
\text { score } \\
\text { AAOS } \\
\text { AOFAS } \\
\text { FAI score }\end{array}$ & 1,3 and 6 months. \\
\hline $\begin{array}{l}\text { Uğurlar et al } \\
2018^{47}\end{array}$ & $\begin{array}{l}\text { Randomised, open label, } \\
\text { four arms, parallel }\end{array}$ & Turkey & Yes & Yes & 39 & 40 & $\begin{array}{l}\text { VAS } \\
\text { FFI-R }\end{array}$ & $\begin{array}{l}1,3,6,12,24 \text { and } \\
36 \text { months }\end{array}$ \\
\hline $\begin{array}{l}\text { Acosta-Olivo et al } \\
2017^{48}\end{array}$ & $\begin{array}{l}\text { Randomised, double } \\
\text { blinded, two arms, } \\
\text { parallel }\end{array}$ & $\begin{array}{l}\text { Mexico. } \\
\text { Hospital based }\end{array}$ & Yes & Yes & 14 & 14 & $\begin{array}{l}\text { VAS } \\
\text { FADI } \\
\text { AOFAS }\end{array}$ & $\begin{array}{l}2,4,8,12 \text { and } 16 \\
\text { weeks }\end{array}$ \\
\hline $\begin{array}{l}\text { Mahindra et al } \\
2016^{49}\end{array}$ & $\begin{array}{l}\text { Randomised, single } \\
\text { blinded, three arms, } \\
\text { parallel trial }\end{array}$ & $\begin{array}{l}\text { India. } \\
\text { Hospital based }\end{array}$ & Yes & Yes & 25 & 25 & $\begin{array}{l}\text { VAS } \\
\text { AOFAS }\end{array}$ & 3 and 12 weeks \\
\hline $\begin{array}{l}\text { Jain K. et al } \\
2015^{(50)}\end{array}$ & $\begin{array}{l}\text { Randomised, open label, } \\
\text { two arms, parallel }\end{array}$ & $\begin{array}{l}\text { UK. } \\
\text { Hospital based }\end{array}$ & Not specified & $\begin{array}{l}\text { Not } \\
\text { specified }\end{array}$ & 24 & 22 & $\begin{array}{l}\text { VAS } \\
\text { Roles and Maudsley } \\
\text { score } \\
\text { AOFAS }\end{array}$ & $\begin{array}{l}3,6 \text {, and } 12 \\
\text { months }\end{array}$ \\
\hline Sherpy et al 2015 & $\begin{array}{l}\text { Randomised, double } \\
\text { blinded, two arms, } \\
\text { parallel }\end{array}$ & $\begin{array}{l}\text { Egypt. } \\
\text { Hospital based }\end{array}$ & Yes & Yes & 25 & 25 & $\begin{array}{l}\text { VAS } \\
\text { FHSQ } \\
\text { Plantar fascia } \\
\text { thickness on } \\
\text { Ultrasound }\end{array}$ & 1.5 and 3 months \\
\hline $\begin{array}{r}\text { Tiwari et al } \\
2013^{(52)}\end{array}$ & $\begin{array}{l}\text { Randomised, open label, } \\
\text { two arms, parallel }\end{array}$ & $\begin{array}{l}\text { India. } \\
\text { Hospital based }\end{array}$ & Yes & Yes & 30 & 30 & VAS & 1,3 and 6 months \\
\hline $\begin{array}{l}\text { Omer et al } \\
\qquad 2012^{(53)}\end{array}$ & $\begin{array}{l}\text { Randomised, open label, } \\
\text { two arms, parallel }\end{array}$ & $\begin{array}{l}\text { Egypt. } \\
\text { Hospital based }\end{array}$ & Not specified. & $\begin{array}{l}\text { Not } \\
\text { specified }\end{array}$ & 30 & 30 & $\begin{array}{l}\text { VAS } \\
\text { FSHQ score }\end{array}$ & $\begin{array}{l}3 \text { weeks and } 6 \\
\text { months }\end{array}$ \\
\hline $\begin{array}{l}\text { Akşahine al } \\
2012^{(54)}\end{array}$ & $\begin{array}{l}\text { Quasi randomised, single } \\
\text { blinded, two arms, } \\
\text { parallel }\end{array}$ & $\begin{array}{l}\text { Turkey. } \\
\text { Hospital based }\end{array}$ & Yes & Yes & 15 & 15 & $\begin{array}{l}\text { VAS } \\
\text { Roles and Maudsley } \\
\text { score. }\end{array}$ & $\begin{array}{l}3 \text { weeks and } 6 \\
\text { months }\end{array}$ \\
\hline
\end{tabular}

In case of significant heterogeneity present, further appropriate subgroup analysis was performed based on method of PRP preparation, Statistical algorithms, in accordance with Cochrane Collaboration guidelines, were used to calculate the standard deviations from the available data for eligible studies that lacked standard deviation of the mean values. Meta-analysis was performed using RevMan version 5.3.

\section{Results}

\subsection{Study selection}

Searching the databases (pubmed, Chochrane databases, Embase, Web of Science collection, and clinicaltrials.gov) led to retrieval of 509 studies. Duplicates were removed and 340 studies remained. Thorough screening of titles and abstracts led to exclusion of 305 records. Full texts of the remaining studies were fully reviewed and 10 studies were deemed suitable for inclusion (Fig. 1).

\subsection{Study characteristics}

The characteristics of the included studies are summarised in Table 3. The studies included were published between 2012 and 2019. The trial design in each study was parallel group design; five were openlabel, three double blinded, and two studies were single blinded. Sample size ranged from 30 to 80 patients. All studies that included patients with plantar fasciitis, who had failed a trial of conservative management for at least 3 months, and patients with history of surgical intervention for plantar fasciitis were excluded.

Total number of participants was 543, ranging from 30 to 80 patients in each arm of the included studies. The mean age of patients included in the studies ranged between 30.7 and 51.0 years in the CS groups compared to 33.9-59.0 years in the PRP group. All studies used clinical features to diagnose plantar fasciitis but 3 studies used further imaging in form of US or MRI ${ }^{47,48,51}$ Amongst the included studies, only one study utilized US guidance for administration of injection in both PRP and CS groups. ${ }^{47}$ All intervention groups, received one session of either PRP or CS injection apart from on study ${ }^{47}$, where intervention were provided to participants in three separate sessions, seven days apart.

With the exception of three studies ${ }^{47,52,53}$ all studies enrolled patients into a programme of stretching exercises post injection.

Details of intervention methods used for both groups are outlined in Table 4. VAS score was used for outcome measurement in all studies.

\subsection{Risk of bias}

Cochrane risk of bias tool ${ }^{55}$ was used to assess for risk of bias in individual studies. The main categories in which there was a high risk of bias was blinding of participants and personnel and allocation concealment noted in 3 different studies for each item. No published protocol was found for any of the studies included was the only reason to judge selective outcome reporting as unclear. The overall risk of bias for individual studies, rational for judgment are summarised in Fig. 2 and Fig. 3.

\subsection{Comparison of VAS score}

The pooled results of weighted mean difference (WMD) of VAS 


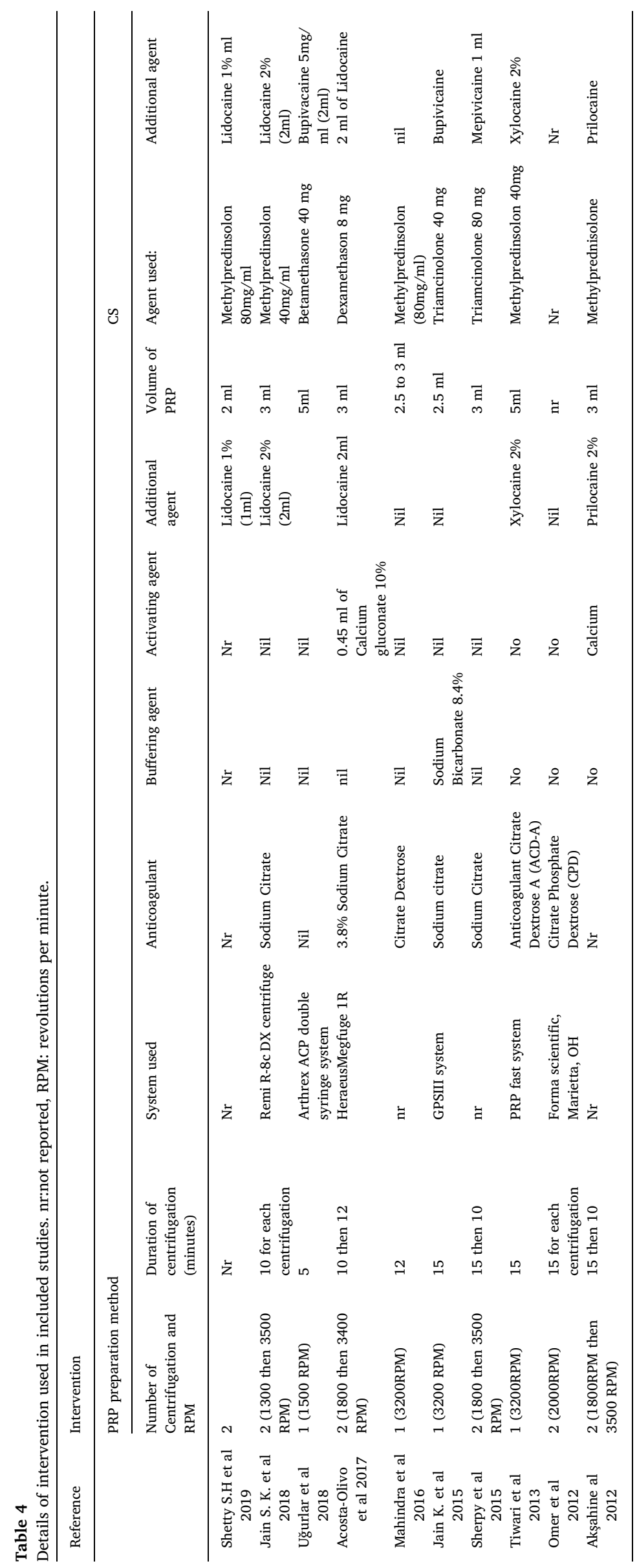




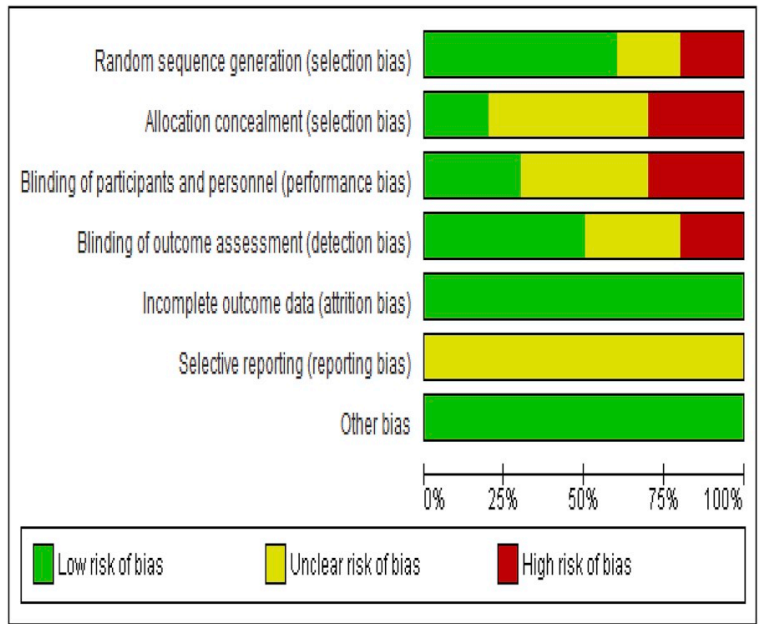

Fig. 2. Risk of bias graph: review authors' judgements about each risk of bias item presented as percentages across all included studies.

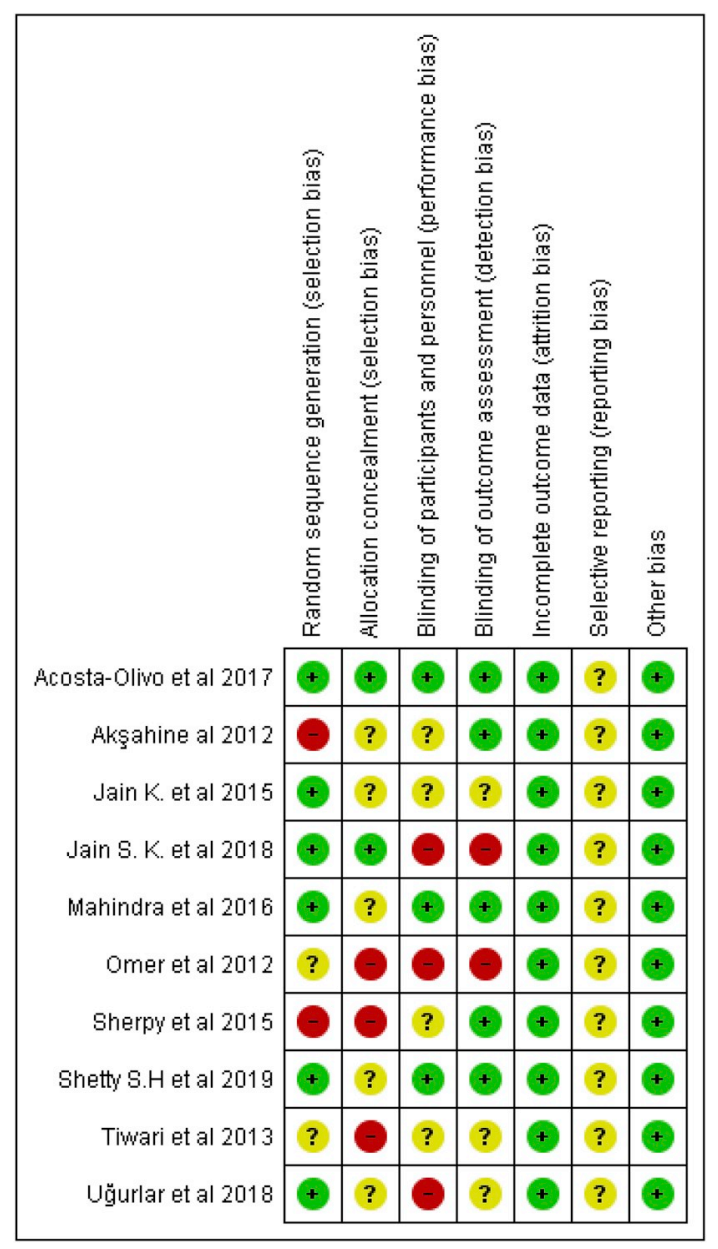

Fig. 3. Risk of bias summary: review authors' judgements about each risk of bias item for each included study.

derived from included studies were compared at three intervals: 4 weeks, 3 months and 6 months (Fig. 4).

There was no significant difference in VAS score between the two groups at 4 weeks follow-up (WMD:0.98, 95\%CI: -0.38,2.33, P: 0.16).

At three months follow up, VAS scores were significantly improved in the PRP group (WMD, -1 ; $95 \% \mathrm{CI}$ : -1.8 to -0.19 ; $\mathrm{p}=0.02$ ).

Significant improvement was maintained in the PRP group at 6 months follow up (WMD: -1.32 ; 95\% CI: -2.33 to -0.31 ; $=0.01$ ).

Significant heterogeneity between studies was noted for the mean difference of VAS score between the groups at all points of follow up change in HbA1c (Tau2: 1.74; I2: 91\%; P < 0.001).

The funnel plot showed a symmetrical pattern of effect estimate distribution, among included studies, indicating low risk of publication bias (Fig. 5).

\subsection{Sensitivity and subgroup analysis}

To explore heterogeneity, we conducted a sensitivity analysis by removing each study individually and observing the effect on the pooled estimate. VAS score pooled results were stable during the process and no significant change was noticed to the level of heterogeneity.

Overall VAS pooled estimate was compared between subgroup of studies which used double centrifugation technique and studies utilized single centrifugation method (Fig. 6). VAS WMD difference outcome showed significant beneficial effect of PRP injection in both subgroups of the studies (Double centrifugation method: WMD, $-1.67 ; 95 \% \mathrm{CI}$ : -2.93 to $-0.5 ; \mathrm{p}=0.01$, Single Centrifugation method: WMD, -1.16 ; $95 \%$ CI: -2.05 to $-0.27 ; \mathrm{p}=0.01$ ), however, no significant difference between the subgroups was found (P: 0.52). Moreover, significant heterogeneity of effect estimates persists between double and single centrifugation techniques $(\mathrm{P}<0.01)$ with $\mathrm{I}^{2}: 84 \%$ and $83 \%$, respectively.

\section{Discussion}

\subsection{Evidence summary}

Plantar fasciitis is a very common condition, with estimated annual cost of treatment around \$284 million in the United States. ${ }^{2}$ Different treatment modalities were described for the condition like: ESWL, prolotherapy, CS injection, Botox injection and PRP injection with no agreement has been reached about the best treatment modality to be used for plantar fasciitis, and the results of the different treatments have been inconsistent and subject to controversy. ${ }^{56}$ There is a growing recent interest for PRP injection as a possibly highly successful treatment of plantar fasciitis. This notion stemmed from the better understanding of plantar fasciitis pathology as a degenerative process which may lack accompanying inflammatory element ${ }^{6}$ which led to more widespread acceptance of PRP injection for treatment of plantar fasciitis with promising beneficial long term effect compared to other modalities of non-operative treatment, including, CS injection that is commonly used in an attempt to address the inflammatory component only of the condition.

VAS score was used as the main outcome to measure intervention efficacy despite the argument of its subjectivity, rendering it as unreliable measurement tool for treatment outcome in plantar fasciitis according to authors who believe in the more objective functional outcome measurement tool. We believe that VAS score is a very useful measurement tool to be used in plantar fasciitis reflecting the reality of clinical practice, where the main health impact of plantar fasciitis is pain leading affected individuals to refrain from activities. Additionally, the simplicity of VAS score compared to other functional outcome score, like FADI, FAS, AOFAS, made it widely used in clinical setting by health care provider for pain assessment.

The results of our study support the theoretical assumption of long term beneficial effect of PRP injection. At 4 weeks there was no significant difference in WMD of VAS between the groups (WMD: 0.98, [95\% CI: $-0.38,2.33$ ] $\mathrm{P}=0.16$ ). Significant VAS improvement among PRP group at 3 months follow up was noticed (WMD: 1, [95\% CI: $1.82,-0.19], P=0.02$ ). Furthermore, significant WMD of VAS score pooled estimate at 6 months was sustained (WMD: 1.32, [95\% CI: $-2.33,-0.32$ ] $\mathrm{P}=0.01$ ).

Comparable finding was reported by a similar systematic review 


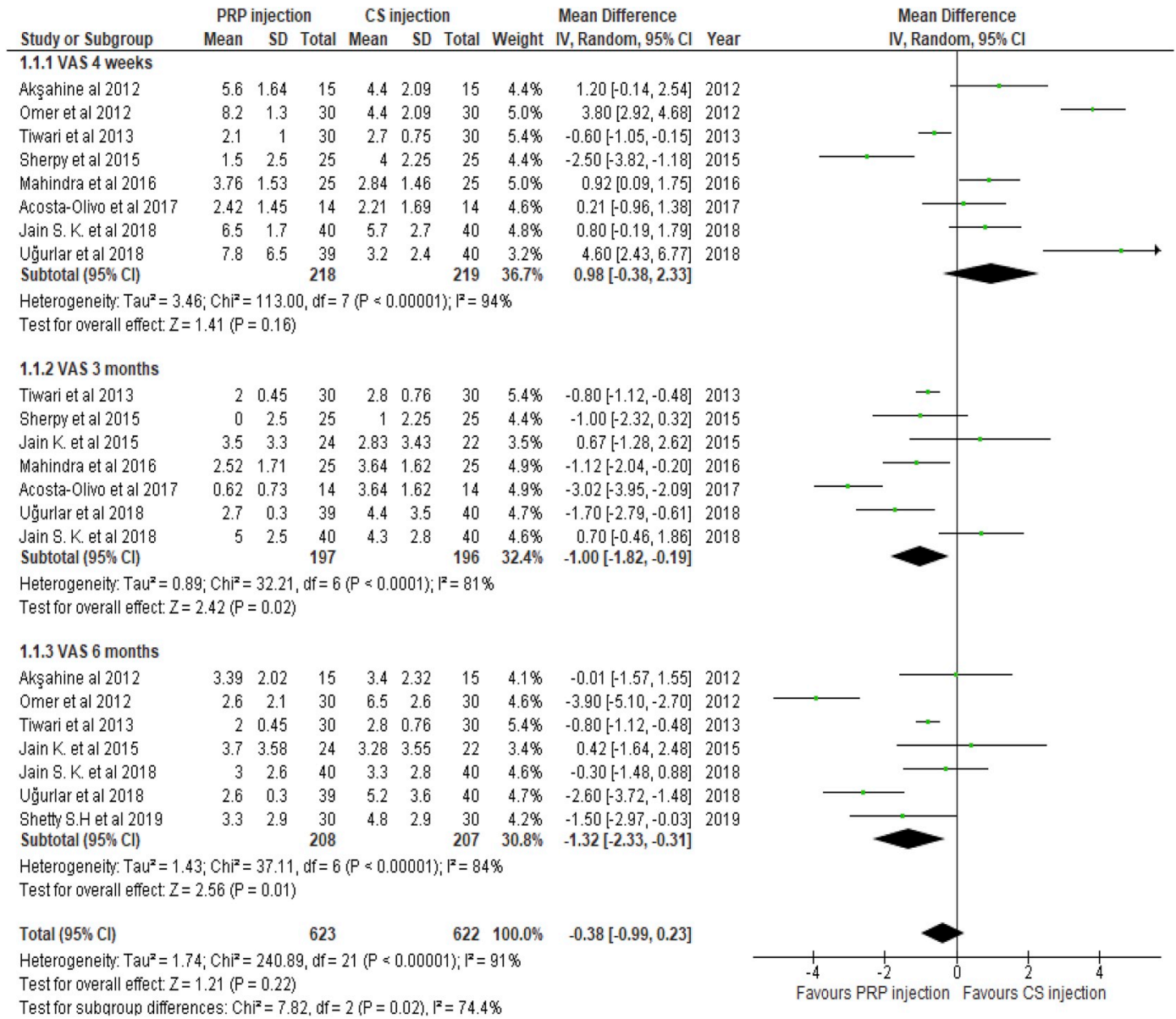

Fig. 4. Forest plot of primary end points comparison (VAS scores at 1, 3 and 6 months' follow-up between PRP injection group and CS injection group).

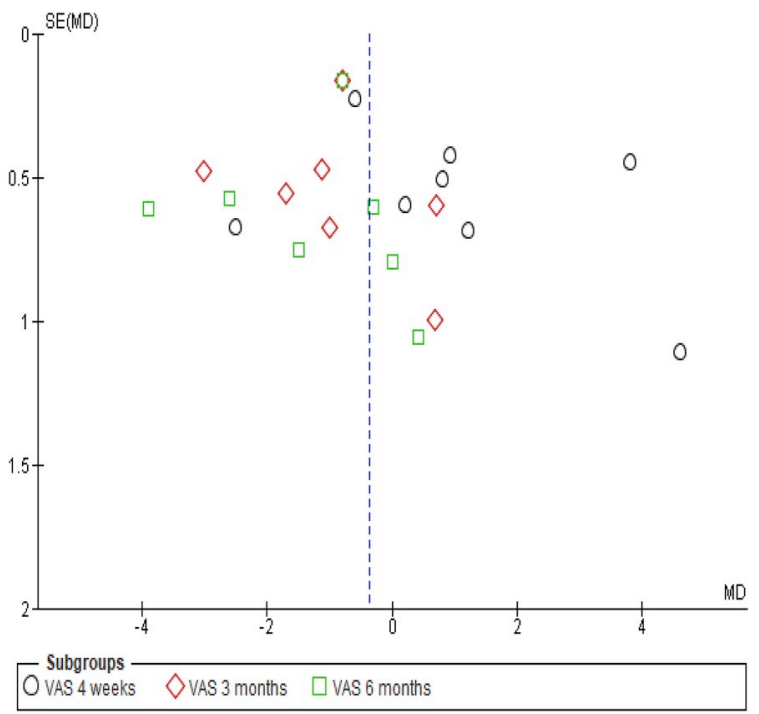

Fig. 5. Funnel plot of VAS comparison (PRP injection Vs CS injection).

carried out by Singh et al. ${ }^{57}$ where significant improvement of VAS score standardized mean difference (SMD) was reported at 3 months follow up (SMD, $-0.66 ; 95 \% \mathrm{CI},-1.3$ to $-0.02 ; \mathrm{p}=0.04 \mathrm{I}^{2}=86 \%$ ), however, no difference was found neither at 4 weeks nor at 6 months follow up. On the other hand, Yang et al. ${ }^{58}$ reported no statistically significant difference of VAS score neither at short term (4 weeks) nor Intermediate term ( 3 months), but significant improvement reported at long term (6 months) follow up (WMD $=-0.95,95 \% \mathrm{CI}$ : -1.80 to $\left.-0.11, P=0.03, \mathrm{I}^{2}=85 \%\right)$. Despite the obvious disparity of results from the two Systematic review and meta-analysis cited, there is a trend to agree on longer term improvement following PRP injection, however significant heterogeneity of high level was noticed in both studies, which make reaching a definitive conclusion not yet possible.

Plantar fasciitis underlying pathology is of degenerative nature with presence of small tears that cannot heal promptly due to hypo vascularity of the plantar fascia, which preclude the delivery of growth factors and platelets to promote healing process, resulting in persistence of such lesions. ${ }^{59}$ PRP is prepared by centrifugation of a sample of blood resulting in supraphysiological concentration of cytokines and growth factors, which may play an important role in the treatment of PF by initiating the healing stages and reversal of the degenerative process. ${ }^{42}$ A minimum increase by 4 times of the baseline is needed in order to achieve clinical efficacy (1million platelets/ $\mu$ l) as proven by different studies and different systems are used to prepare PRP with slight variability in their ability to concentrate platelets depending on the manufacturer's system used. ${ }^{40}$ The studies included in this analysis were subject to significant statistical heterogeneity. Marked variation was observed in the preparation methods of PRP, and variability in using buffering agent or platelets activating agent, which is believed to maximize growth factors and cytokines release from platelets, could be an underlying reason for the significant level of heterogeneity noticed.

In our study, we considered the possibility of the PRP preparation method as a possible underlying cause for observed heterogeneity among included studies. Subgroup analysis was performed between studies using double centrifugation method compared to single centrifugation method for PRP preparation. No statistically significant difference was found between the subgroups $\left(\mathrm{Chi}^{2}{ }^{2} 0.42, \mathrm{P}=0.52\right)$ and significant level of heterogeneity was noted in both double 


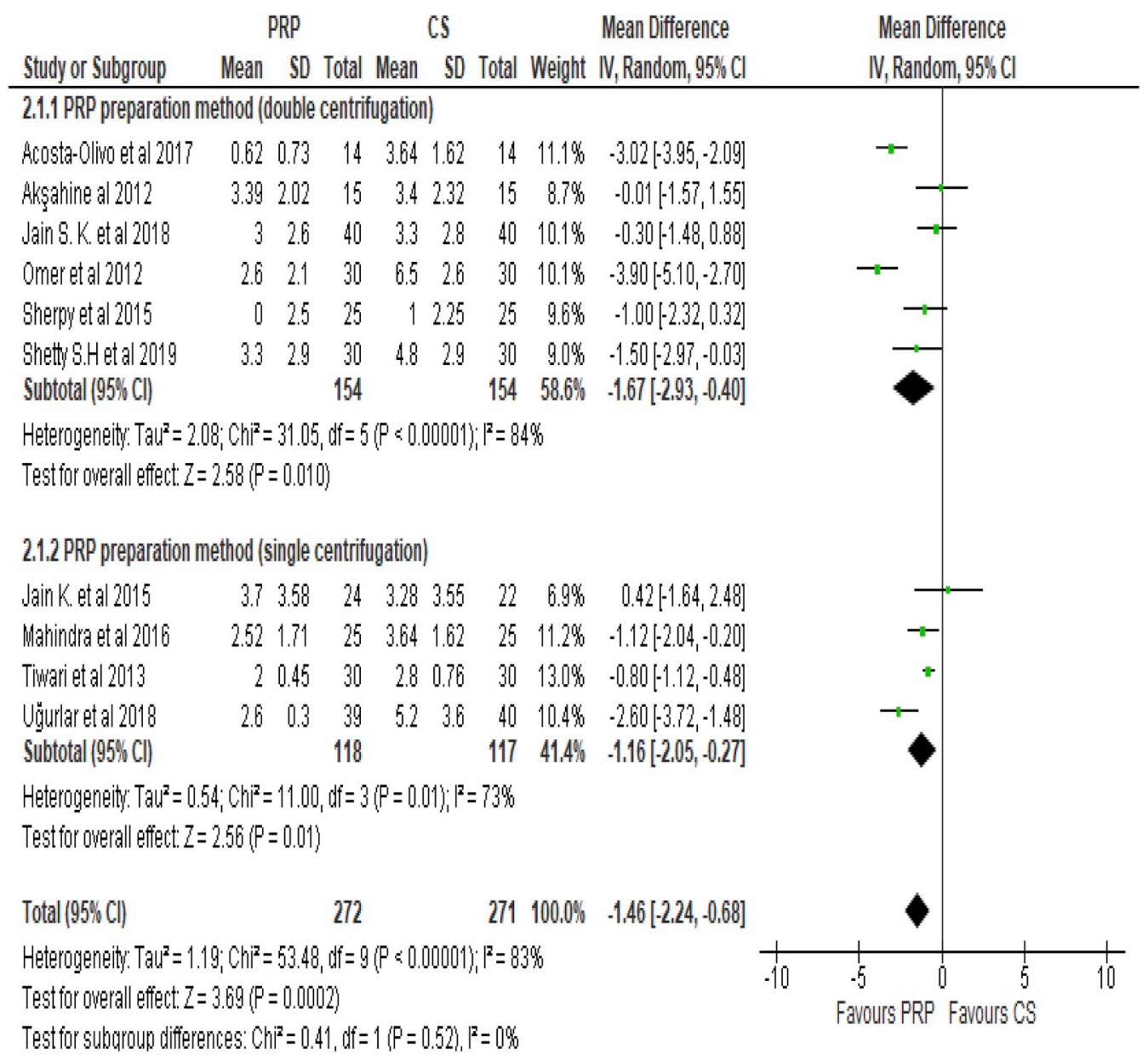

Fig. 6. Forest plot of subgroup analysis (VAS comparison of PRP vs CS injection sub grouped by PRP preparation method).

centrifugation and single centrifugation subgroups ( $\mathrm{I}^{2}: 84 \%$ vs $73 \%$, respectively).

\subsection{Strengths and limitation}

The small number of studies included was the main shortcoming of the study with total number of participants of 543. Moreover the sample size were relatively small in each individual study ranging between 30 and 80 participants which we believe is not sufficiently large to draw credible conclusion.

In our study we aimed to capture the reality by including studies with most accurate estimates of PRP injection outcome that is credible and clinically applicable. For this reason, we decided to include RCT and studies which are not RCT by design or have rigorous methodological approach, resulting in increased risk of bias as shown in the risk of bias assessment done for included studies. However, we felt randomisation is essential part of the prospective trial included, therefore, only studies in which randomisation was done or actively sought by the researcher was included, in order to ensure even distribution of the baseline confounder to facilitate comparison of outcomes post injection compared to pre injection. This led to a reduction in the number of studies included in the meta-analysis. The decision to limit outcome assessment to VAS score, to facilitate further comparison in clinical setting, led to further exclusion of trials, with further adverse impact on the number of trials included for the Purpose of the meta-analysis.

Overall, we believe this is the most updated systematic review done,that encompass all studies published comparing PRP injection to CS injection in plantar fasciitis, and of reasonable approach in selecting studies in order not to over- or underestimate the efficacy of PRP injection.

\section{Conclusion}

In Summary, our study showed that PRP injection led to improved pain score compared to CS injection among patients diagnosed with plantar fasciitis at three months and six months follow up but no difference was found at 4 weeks follow up.

Due to paucity of data beyond six months period in the included study, it was not possible to assess long term outcome and recurrence of pain for both modalities of treatment. Therefore, we recommend larger, well designed randomised controlled trials with longer follow up in order to reach more conclusive results of the PRP efficacy compared to CS injection and to assess for recurrence rate among both treatment modalities.

\section{Declaration of competing interest}

This research did not receive any specific grant from funding agencies in the public, commercial, or not-for-profit sector.

\section{References}

1. Riddle DL, Schappert SM. Volume of ambulatory care visits and patterns of care for patients diagnosed with plantar fasciitis: a national study of medical doctors. Foot Ankle Int. 2004 May;25(5):303-310.

2. Tong KB, Furia J. Economic burden of plantar fasciitis treatment in the United States. Am J Orthoped. 2010 May;39(5):227-231.

3. D'Ambrogi E, Giurato L, D'Agostino MA, et al. Contribution of plantar fascia to the increased forefoot pressures in diabetic patients. Diabetes Care. 2003 
May;26(5):1525-1529.

4. Gefen A. The in vivo elastic properties of the plantar fascia during the contact phase of walking. Foot Ankle Int. 2003 Mar;24(3):238-244.

5. Dimarcangelo MT, Yu TC. Diagnostic imaging of heel pain and plantar fasciitis. Clin Podiatr Med Surg. 1997;14:284.

6. Lemont H, Ammirati KM, Usen N. Plantar fasciitis: a degenerative process (fasciosis) without inflammation. J Am Podiatr Med Assoc. 2003 Jun;93(3):234-237.

7. Dimarcangelo MT, Yu TC. Diagnostic imaging of heel pain and plantar fasciitis. Clin Podiatr Med Surg. 1997;14:284

8. Cutts S, Obi N, Pasapula C, Chan W. Plantar fasciitis. Ann R Coll Surg Engl. 2012 Nov;94(8):539-542.

9. Grasel RP, Schweitzer ME, Kovalovich AM, et al. MR imaging of plantar fasciitis: edema, tears, and occult marrow abnormalities correlated with outcome. AJR Am J Roentgenol. 1999 Sep;173(3):699-701.

10. Riddle DL, Pulisic M, Pidcoe P, Johnson RE. Risk factors for Plantar fasciitis: a matched case-control study. J Bone Joint Surg Am. 2003 May;85(5):872-877.

11. Gill null. Plantar fasciitis: diagnosis and conservative management. J Am Acad Orthop Surg. 1997 Mar;5(2):109-117.

12. Irving DB, Cook JL, Young MA, Menz HB. Impact of chronic plantar heel pain on health-related quality of life. J Am Podiatr Med Assoc. 2008;9:11-22.

13. Buckbinder R. Plantar fasciitis. N Engl J Med. 2004;350:2159-2166.

14. McMillan AM, Landorf KB, Gilheany MF, Bird AR, Morrow AD, Menz HB. Ultrasound guided corticosteroid injection for plantar fasciitis: randomized controlled trial. $\mathrm{Br}$ Med J. 2012;344:e3260.

15. Hill CL, Tiffany KG, Menz HB, Taylor AW. Prevalence and correlates of foot pain in population-based study: the North West Adelaide health study. J Foot Ankle Res. 2008;1:2.

16. Rajasekaran S, Finnoff JT. Plantar fasciopathy: a clinical review. Curr Phys Med Rehabilit Rep. 2015 Mar 1;3(1):67-76.

17. Lareau CR, Sawyer GA, Wang JH, DiGiovanni CW. Plantar and medial heel pain: diagnosis and management. J Am Acad Orthop Surg. 2014;22:372-380.

18. Wolgin M, Cook C, Graham C, Mauldin D. Conservative treatment of plantar heel pain: long-term follow-up. Foot Ankle Int. 1994;15:97-102.

19. Buchbinder R. Clinical practice. Plantar fasciitis. N Engl J Med. 2004;350:2159-2166.

20. Beeson P. Plantar fasciopathy: revisiting the risk factors. Foot Ankle Surg. 2014 Sep;20(3):160-165.

21. Neufeld SK, Cerrato R. Plantar fasciitis: evaluation and treatment. J Am Acad Orthop Surg. 2008;16:338-346

22. Osborne HR, Breidahl WH, Allison GT. Critical differences in lateral X-rays with and without a diagnosis of plantar fasciitis. J Sci Med Sport. 2006;9:231-237.

23. McNally EG, Shetty S. Plantar fascia: imaging diagnosis and guided treatment. Semin Musculoskelet Radiol. 2010;14:334-343.

24. Theodorou DJ, Theodorou SJ, Resnick D. MR imaging of abnormalities of the plantar fascia. Semin Musculoskelet Radiol. 2002;6(2):105-118.

25. DiGiovanni BF, Nawoczenski DA, Lintal ME, et al. Tissue-specific plantar fasciastretching exercise enhances outcomes in patients with chronic heel pain. A prospective. J Bone Joint Surg Am. 2003;85(7):1270-1277. https://doi.org/10.2106/ 00004623-200307000-00013.

26. Podolsky R, Kalichman L. Taping for plantar fasciitis. J Back Musculoskelet Rehabil 2014. https://doi.org/10.3233/BMR-140485.

27. Hyland MR, Webber-Gaffney A, Cohen L, Lichtman PT. Randomized controlled trial of calcaneal taping, sham taping, and plantar fascia stretching for the short-term management of plantar heel pain. J Orthop Sports Phys Ther. 2006;36:364-371.

28. Barry LD, Barry AN, Chen Y. A retrospective study of standing gastrocnemius-soleus stretching versus night splinting in the treatment of plantar fasciitis. J Foot Ankle Surg. 2002;41:221-227.

29. Pfeffer G, Bacchetti P, Deland J, et al. Comparison of custom and prefabricated orthoses in the initial treatment of proximal plantar fasciitis. Foot Ankle Int. 1999;20:214-221.

30. Batt ME, Tanji JL, Skattum N. Plantar fasciitis: a prospective randomized clinical trial of the tension night splint. Clin J Sport Med. 1996;6:158-162.

31. Lee WC, Wong WY, Kung E, Leung AK. Effectiveness of adjustable dorsiflexion night splint in combination with accommodative foot orthosis on plantar fasciitis. J Rehabil Res Dev. 2012;49:1557-1564.

32. Speed C. A systematic review of shockwave therapies in soft tissue conditions: focusing on the evidence. Br J Sports Med. 2014 Nov;48(21):1538-1542.

33. Furey JG. Plantar fasciitis. The painful heel syndrome. J Bone Joint Surg Am. 1975;57:672-673.

34. Crawford F, Atkins D, Young P, Edwards J. Steroid injection for heel pain: evidence of short-term effectiveness. A randomized controlled trial. Rheumatology.
1999;38:974-977.

35. Yucel I, Yazici B, Degirmenci E, Erdogmus B, Dogan S. Comparison of ultrasound-, palpation-, and scintigraphy-guided steroid injections in the treatment of plantar fasciitis. Arch Orthop Trauma Surg. 2009;129:695-701.

36. Acevedo JI, Beskin JL. Complications of plantar fascia rupture associated with corticosteroid injection. Foot Ankle Int. 1998;19:91-97.

37. Brinks A, Koes BW, Volkers AC, Verhaar JA, Bierma-Zeinstra SM. Adverse effects of extra-articular corticosteroid injections: a systematic review. BMC MusculoskeletDisord. 2010;11:206.

38. Maida E, Presley JC, Murthy N, Pawlina W, Smith J. Sonographically guided deep plantar fascia injections: where does the injectate go? J Ultrasound. 2013;32:1451-1459.

39. Everts P, Knape J, Weirich G, et al. Platelet-rich plasma and platelet gel: a review. $J$ ECT. 2006;38:174-187.

40. Marx RE. Platelet-rich plasma: evidence to support its use. J Oral Maxillofac Surg. 2004 Apr 1;62(4):489-496.

41. Sampson S, Gerhardt M, Mandelbaum B. Platelet rich plasma injection grafts for musculoskeletal injuries: a review. Curr Rev Musculoskelet Med. 2008 Dec;1(3-4):165-174.

42. Molloy T, Wang Y, Murrell G. The roles of growth factors in tendon and ligament healing. Sports Med. 2003;33(5):381-394.

43. Antitua E, Andia I, Sanchez M, et al. Autologous preparations rich in growth factors promote proliferation and induce VEGF and HGF productions by human tendon cells in culture. J Orthop Res. 2005;23:281-286.

44. Barrett S, Erredge S. Growth factors for chronic plantar fascitis. Podiatry Today. 2004;17:37-42.

45. Shetty SH, Dhond A, Arora M, Deore S. Platelet-rich plasma has better long-term results than corticosteroids or placebo for chronic plantar fasciitis: randomized control trial. J Foot Ankle Surg. 2019;58(1):42-46.

46. Jain S, Suprashant K, Kumar S, Yadav A, Kearns S. Comparison of plantar fasciitis injected with platelet-rich plasma vs corticosteroids. Foot Ankle Int/Am Orthopaed Foot Ankle Soc Swiss Foot Ankle Soc. 2018;39(7):780-786.

47. Uğurlar M, Sönmez MM, Öy Uğurlar, Adıyeke L, Yıldırım H, Eren OT. Effectiveness of four different treatment modalities in the treatment of chronic plantar fasciitis during a 36-month follow-up period: a randomized controlled trial. J Foot Ankle Surg. 2018 Sep;57(5):913-918.

48. Acosta-Olivo C, Elizondo-Rodriguez J, Lopez-Cavazos R, Vilchez-Cavazos F, Simental-Mendia M, Mendoza-Lemus O. Plantar fasciitis-A comparison of treatment with intralesional steroids versus platelet-rich plasma A randomized, blinded study. $J$ Am Podiatr Med Assoc. 2017;107(6):490-496.

49. Mahindra P, Yamin M, Selhi HS, Singla S, Soni A. Chronic plantar fasciitis: effect of platelet- rich plasma, corticosteroid, and placebo. Orthopedics. 2016;39(2):e285-e289

50. Jain K, Murphy P, Clough T. Platelet rich plasma versus corticosteroid injection for plantar fasciitis: a comparative study. Foot. 2015;25(4):235-237.

51. Sherpy NA, Hammad MA, Hagrass HA, Samir H, Abu-ElMaaty SE, Mortada MA. Local injection of autologous platelet rich plasma compared to corticosteroid treatment of chronic plantar fasciitis patients: a clinical and ultrasonographic follow-up study. Egypt Rheumatol. 2016;38(3):247-252.

52. Tiwari M, Bhargava R. Platelet rich plasma therapy: a comparative effective therapy with promising results in plantar fasciitis. J ClinOrthopTraum. 2013;4(1):31-35.

53. Omar A, Ibrahim M, Ahmed A, Said M. Local injection of autologous platelet rich plasma and corticosteroid in treatment of lateral epicondylitis and plantar fasciitis: randomized clinical trial. Egyptian rheumatologist. 2012;34(2):43-49.

54. Akoahin E, Doğruyol D, Yüksel HY, et al. The comparison of the effect of corticosteroids and platelet-rich plasma (PRP) for the treatment of plantar fasciitis. Arch Orthop Trauma Surg. 2012;132(6):781-785.

55. Guide to the contents of a Cochrane protocol and review. In: Higgins JPT, Green S, eds. The Cochrane Handbook for Systematic Reviews of Interventions. Wiley-Blackwell; 2011.

56. Porter MD, Shadbolt B. Intralesional corticosteroid injection versus extracorporeal shock wave therapy for plantar fasciopathy. Clin J Sport Med. 2005;15:119-124.

57. Singh P, Madanipour S, Bhamra JS, Gill I. A systematic review and meta-analysis of platelet-rich plasma versus corticosteroid injections for plantar fasciopathy. Int Orthop. 2017;41(6):1169-1181.

58. Yang W, Han Y, Cao X, et al. Platelet-rich plasma as a treatment for plantar fasciitis: a meta-analysis of randomized controlled trials. Medicine. 2017 Nov;96(44):e8475.

59. Fenwick SA, Hazleman BL, Riley GP. The vasculature and its role in the damaged and healing tendon. Arthritis Res. 2002;4:252-260. 